\title{
Flow cytometric and microscopic evaluation and effect on fertility of abnormal chromatin condensation in bovine sperm nuclei
}

\author{
I. Dobrinski ${ }^{1 *}$, H. P. A. Hughes ${ }^{2}$ and A. D. Barth ${ }^{1}$ \\ ${ }^{1}$ Department of Herd Medicine and Theriogenology, Western College of Veterinary Medicine, University \\ of Saskatchewan; and ${ }^{2}$ Veterinary Infectious Disease Organization, Saskatoon, SK, Canada, S7N OWO
}

\begin{abstract}
The techniques of Feulgen staining, acridine orange staining, and a sperm chromatin structure assay using acridine orange and flow cytometry were compared for selective examination of bovine sperm nuclei. Twenty frozen semen samples were simultaneously analysed by all three methods. The prevalence of abnormally condensed DNA and its relationship to other semen traits were determined in ejaculates from 70 bulls presented for routine examination for breeding soundness and in frozen semen from 348 bulls evaluated over five years. A breeding trial with 118 beef heifers using semen from six bulls with different degrees of nuclear abnormalities was performed to assess the importance of the defects with respect to fertility. The results indicate that few spermatozoa with abnormal DNA condensation are found in normal semen, but the incidence increases with disturbance of spermatogenesis. However, high numbers of abnormally condensed nuclei were found in the absence of an increase in other defects. This nuclear defect might be at least partially of epididymal origin; it can lower fertility and can be compensated for by increasing the numbers of normal spermatozoa in the insemination dose. The percentage of abnormally condensed sperm nuclei as detected by Feulgen staining was significantly correlated with that detected by microscopy after acridine orange staining and by the sperm chromatin structure assay. We therefore consider the Feulgen technique to be a valuable tool for assessing the nuclear integrity of bovine spermatozoa.
\end{abstract}

\section{Introduction}

The DNA in mammalian sperm nuclei is bound to basic nuclear proteins to form the deoxyribonuclear-protein (DNP) complex. The diffuse chromatin characteristic of genetically active germ cells becomes highly condensed and biochemically inert in the last stages of spermatogenesis (Wagner and Minhas, 1982). Concomitant with these changes the lysine-rich histones are removed from the DNA and are replaced by arginine-rich protamines. Mammalian protamines contain cysteine residues, which form disulfide crosslinks between adjacent protamine molecules during the final stages of chromatin maturation. Mature bovine spermatozoa contain only protamine 1, which forms two intramolecular and three intermolecular disulfide crosslinks (Balhorn et al., 1991). The protamines seem to bind in the minor groove of one turn of the DNA helix. The protamine-DNA complex of one strand then fits into the major groove of an adjacent strand, allowing the strands to be packaged side by side in a linear array; the DNA in sperm nuclei is then six times more condensed than the DNA in the mitotic chromosome (Ward and Coffey, 1991). The process of DNA condensation may be incomplete, resulting in a less

*Correspondence: Department of Clinical Sciences, Section Theriogenology, College of Veterinary Medicine, Cornell University, Ithaca, NY 14853-6401, USA.

Received 2 September 1993. stable nucleus and increased susceptibility to denaturation of the DNP complex (Gledhill et al., 1966, 1971; Darzynkiewicz et al., 1969; Brachet and Hulin, 1969).

Acridine orange has been used for selective staining of sperm nuclear chromatin in conjunction with flow cytometry for detection of spermatozoa with abnormal DNA condensation. Acridine orange is a tricyclic heteroaromatic dye that fluoresces green when bound to double-stranded DNA by intercalation. High-binding density of acridine orange to RNA or single-stranded (denatured) DNA results in a metachromatic shift towards red luminescence (Darzynkiewicz and Kapuscinski, 1990). A sperm chromatin structure assay (SCSA) has been established using flow cytometric measurement of acridine orange fluorescence in double-stranded compared with single-stranded DNA, after denaturation of nuclear material in situ (Evenson et al., 1980).

The structural stability of sperm nuclear chromatin measured by resistance to denaturation has been shown to be correlated with fertility in bulls (Ballachey et al., 1987, 1988; Karabinus et al., 1990) and pigs (Evenson and Thompson, 1991). A sperm nucleus with DNA partially or fully susceptible to denaturation shows increasing amounts of red fluorescence at the expense of native DNA and green fluorescence. The ratio of red fluorescence to red plus green (total) fluorescence of each cell has been defined as the $\alpha_{t}$-value (Darzynkiewicz et al., 1975). The standard deviation of the $\alpha_{\mathrm{t}}$-distribution (SD $\alpha_{\mathrm{t}}$ ) has been shown 
to correlate with fertility ratings in bulls (Ballachey et al., 1987). Studies in humans (Evenson and Melamed, 1983), mice (Evenson et al., 1985) and bulls (Evenson et al., 1980; Ballachey ef al., 1986) indicate that increased heterogeneity of chromatin structure is associated with disturbances in spermatogenesis, high proportions of morphological abnormalities and infertility.

Abnormal DNA condensation is not detected by examining unstained semen preparations or semen smears prepared using routine morphology stains under the light microscope. However, Feulgen staining is a simple, practical technique that can be used for selective staining of DNP (Feulgen and Rossenbeck, 1924; Gledhill, 1970). Normal sperm nuclei stain homogeneously purplish red, especially when examined by phasecontrast microscopy. Abnormalities such as coarse or fine clumping of the nuclear material can be determined. The existence of clumped granular chromatin has also been shown by electron microscopy (McCosker, 1969; Cran and Massanyi, 1988; Barth and Oko, 1989b). Feulgen staining of human spermatozoa has revealed a higher percentage of heterogeneous DNA distribution in semen from infertile compared with fertile donors (Peluso et al., 1992).

Sperm nuclei with abnormal DNA condensation may be found in small numbers in the semen of normal fertile bulls. The presence of high proportions of these abnormally staining spermatozoa has been associated with decreased fertility (Barth and Oko, 1989b); however, conclusive experimental data correlating DNA condensation problems to infertility in bulls have not yet been reported.

The first objective of the present study was to determine the prevalence of abnormal DNA condensation in bovine semen and its relationship to other sperm defects. The second objective was to compare the Feulgen staining technique and the SCSA for detection and quantification of DNA condensation abnormalities in bovine spermatozoa. The SCSA has been used previously for bovine semen and the results of this assay are expected to be more accurate owing to the objective fluorescence measurement and the large number of cells evaluated per sample. The relationship of the SCSA data to bull fertility could be useful for the interpretation of Feulgenstained semen samples. The third objective was to determine the effect of abnormal chromatin condensation in bovine spermatozoa on their ability to fertilize virgin, feedlot heifers.

\section{Materials and Methods}

\section{Experiment 1}

Animals. The prevalence of abnormally condensed chromatin in sperm nuclei was determined from 69 beef bulls and one dairy bull (with a mean age of $30.6 \pm 2.1$ months) submitted to the Western College of Veterinary Medicine, University of Saskatchewan, Saskatoon, for routine presale or prebreeding evaluations. Semen was collected by electroejaculation (Ott, 1986; Chenoweth et al., 1993). Bulls were classified as satisfactory, questionable or unsatisfactory potential breeders according to the method of the Society for Theriogenology. This classification is based on a physical examination and on minimum requirements for semen quality, including motility (fair gross motility, 30\% individual progressive motility) and morphology (70\% normal) of spermatozoa (Ball et al., 1983; Chenoweth et al., 1993). Bulls are classified as questionable potential breeders if they fail the minimum requirements in one or more categories, but the problem is considered to be transient.

Feulgen stain. Semen smears were made at the time of semen collection and stained by the Feulgen technique within $24 \mathrm{~h}$ of collection (Barth and Oko, 1989a). Briefly, the smears were allowed to dry for at least $2 \mathrm{~h}$ at room temperature and were then exposed to $5 \mathrm{~mol} \mathrm{HCl} \mathrm{I}^{-1}$ for $30 \mathrm{~min}$. After washing the slides in running water for $5 \mathrm{~min}$, the cells were stained in Schiff's reagent (BDH Inc., Toronto) for $45 \mathrm{~min}$. The smears were washed again for $5 \mathrm{~min}$ and allowed to dry. The slides were examined by phase-contrast microscopy at $\times 1000$ magnification and the percentage of normal and abnormal staining spermatozoa was determined by counting at least 300 cells per sample. Sperm abnormalities found were classified into six categories: pyriform heads, giant-rolled-crested heads, palestaining cells, multiple vacuoles, single vacuoles and clumped nuclear material (Barth and Oko, 1989b). Only spermatozoa with clumped nuclear material were classified as abnormally condensed for further comparisons.

Electron microscopy. Selected samples were examined by transmission electron microscopy. The samples were fixed in $5 \%$ glutaraldehyde in $0.1 \mathrm{~mol}$ sodium cacodylate $1^{-1}$, postfixed in reduced osmium tetroxide, dehydrated and embedded in epon-araldite (Hrudka et al., 1991).

Frozen semen analysis. The prevalence of spermatozoa with abnormal chromatin and its relationship to other semen characteristics were retrospectively determined in 571 frozen semen samples from 348 bulls ( 263 beef and 85 dairy bulls) evaluated by the same person over five years. All samples were analysed for post-thaw viability, sperm morphology and the number of motile cells per dose, and were classified using an established routine frozen semen evaluation procedure (Barth, 1989, 1993) and evaluation of Feulgen-stained smears. When multiple samples from the same bull were included in the analysis, the median values for the studied parameters were used. Data were grouped by classification (satisfactory, questionable or unsatisfactory) and by the semen extender used [milk-based extender $(n=84)$ or egg-yolk-based extender $(n=244)]$.

\section{Experiment 2}

Semen samples. Twenty frozen semen samples from bulls of seven different breeds were simultaneously evaluated by flow cytometric analysis of samples stained with acridine orange and by microscopic examination using acridine orange and the Feulgen staining technique. All samples used in this experiment contained $>70 \%$ spermatozoa of normal morphology. Four samples were frozen in milk extender and 16 samples in a yolk-based extender. After the semen had been thawed in a waterbath at $37^{\circ} \mathrm{C}$ for $30 \mathrm{~s}$, three smears per sample were prepared for Feulgen staining as described above. 
Table 1. Results of the breeding trial in Expt 3 using bovine semen with different proportions of spermatozoa with abnormal DNA condensation

\begin{tabular}{lccccc}
$\begin{array}{c}\text { Bull } \\
\text { (number of breedings) }\end{array}$ & $\begin{array}{c}\text { Normal sperm } \\
\text { morphology } \\
(\%)\end{array}$ & $\begin{array}{c}\text { Abnormal } \\
\text { DNA in spermatozoa } \\
(\%)\end{array}$ & $\begin{array}{c}\text { Progressively motile } \\
\text { spermatozoa per dose } \\
\left(\times 10^{6}\right)\end{array}$ & $\begin{array}{c}\text { Progressively motile } \\
\text { spermatozoa with } \\
\text { normal nuclei per dose } \\
\left(\times 10^{\circ}\right)\end{array}$ & $\begin{array}{c}\text { Pregnancy rate on } \\
\text { day 25 after breeding } \\
(\%)\end{array}$ \\
\hline L (31) & $95 \pm 1.0$ & $2 \pm 0.6$ & $16.0 \pm 0.3$ & $15.7 \pm 0.3$ & 52 \\
C (49) & $85 \pm 1.3$ & $7 \pm 0.7$ & $12.0 \pm 0.4$ & $11.2 \pm 0.4$ & 53 \\
H (32) & $82 \pm 0.8$ & $31 \pm 1.3$ & $17.5 \pm 0.3$ & $12.1 \pm 0.3$ & 56 \\
P (45) & $85 \pm 0.5$ & $38 \pm 1.7$ & $14.7 \pm 0.4$ & $9.1 \pm 0.4$ & $34^{*}$ \\
K (43) & $79 \pm 0.5$ & $67 \pm 0.8$ & $11.0 \pm 0.4$ & $3.6 \pm 0.4$ & 40 \\
D (25) & $81 \pm 1.1$ & $75 \pm 1.0$ & $16.0 \pm 0.5$ & $4.0 \pm 0.5$ & 40 \\
\hline
\end{tabular}

*Pregnancy rate is significantly lower than in heifers inseminated with semen from control bulls $\mathrm{L}$ and $\mathrm{C}(P<0.01)$.

Values for semen characteristics are means \pm SEM for $n=5$ evaluations.

Acridine orange stain. Three additional smears were stained with acridine orange according to the method of Tejada et al. (1984), with the modification that slides were exposed to $1 \mathrm{~mol}$ $\mathrm{HCl} \mathrm{I}{ }^{-1}$ for 1 min after fixation in Carnoy's solution. The percentage of green and red fluorescing cells was determined in 300 cells per slide by fluorescence microscopy at $\times 1000$ magnification. The intra-assay coefficient of variation was $9.8 \%$ $(n=10)$.

Flow cytometry. The remaining semen was processed and stained for flow cytometry as described by Evenson (1990) and Ballachey et al. (1987), with some modifications. The semen was diluted without prior washing in a buffer containing

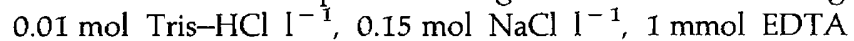
$\mathrm{I}^{-1}, \mathrm{pH} 7.4$, to a final concentration of $10 \times 10^{6}$ cells ml $^{-1}$. An aliquot of $0.2 \mathrm{ml}$ containing $2 \times 10^{6}$ cells was mixed with $0.4 \mathrm{ml}$ of an acid-detergent solution $\left(0.08 \mathrm{~mol} \mathrm{HCl} \mathrm{l}^{-1}\right.$, $0.15 \mathrm{~mol} \mathrm{NaCl} 1^{-1}, 0.1 \%$ Triton-X $100 \mathrm{v} / \mathrm{v}, \mathrm{pH} 1.2$ ) for $30 \mathrm{~s}$. The sample was stained by adding $1.2 \mathrm{ml}$ of the acridine orange staining solution $\left[0.2 \mathrm{~mol} \mathrm{Na}_{2} \mathrm{HPO}_{4} 1^{-1}, 1 \mathrm{mmol}\right.$ EDTA $l^{-1}, 0.15 \mathrm{~mol} \mathrm{NaCll}^{-1}, 0.1 \mathrm{~mol}$ citric acid $l^{-1}, 60 \mu \mathrm{mol}$ acridine orange $\mathrm{I}^{-1}$ (acridine orange, electro pure, Polysciences Inc., Warrington, PA)] and placed in the flow cytometer. This resulted in a ratio of acridine orange molecules to sperm DNA that was lower than that described by Balachey et al. (1987), causing a slightly altered staining pattern.

Data were collected on 10000 cells per sample starting $4 \mathrm{~min}$ after the addition of the dye. All test tubes and solutions were kept on ice; solutions and samples containing acridine orange were wrapped in aluminium foil to minimize exposure to light. Flow cytometry was performed using a FACScan ${ }^{(i i}$ flow cytometer (Becton Dickinson, Rutherford, NJ) equipped with an argon ion laser. Green and red fluorescence emitted by each cell after laser beam excitation ( $15 \mathrm{~mW}, 488 \mathrm{~nm}$ ) was collected using the filter settings designed for cells stained with fluorescein isothiocyanate and phycoerythrin. The collected data were analysed using the Lysys II, Version 1.0 software package (Becton Dickinson, Rutherford, NJ) and a twoparameter histogram was generated for each sample. The raw data were saved in a list mode file and was subsequently converted to create an $\alpha_{\mathrm{t}}$-value, defined as the ratio of red fluorescence to red plus green (total) fluorescence (Darzynkiewicz et al., 1975) for each cell. All samples and control samples were evaluated on the same day to avoid between-day variability (Ballachey et al., 1987). The intra-assay coefficient of variation was $4.2 \%(n=10)$.

Comparison of SCSA and Feulgen stain. Samples were grouped according to the percentage of abnormally condensed chromatin, defined as the clumped appearance of nuclear material observed using the Feulgen technique. Eight samples contained more than $10 \%$, and 12 samples less than $10 \%$ sperm nuclei with abnormally appearing chromatin.

\section{Experiment 3}

Animals and treatments. One hundred and eighteen crossbred beef heifers with an average starting bodymass of $395 \mathrm{~kg}$ were acclimated to a feedlot for one month, and reproductive soundness was confirmed by rectal palpation and ultrasonography. The heifers were kept in the feedlot and were fed concentrate with a choice of alfalfa-grass hay. In 98 heifers oestrus was synchronized with two injections of $500 \mu \mathrm{g}$ cloprostenol i.m. (Estrumate: Cooper's Agropharm Inc., Ajax, Ontario) 12 days apart, and the animals were randomly assigned to be bred by a single insemination with semen from six different bulls, $12 \mathrm{~h}$ after the observed onset of oestrus. The characteristics of the semen used, determined by routine frozen semen evaluation (morphology and motility) and Feulgen staining (abnormal DNA), are shown (Table 1). All heifers were examined for pregnancy by transrectal ultrasonography 25 days after breeding. Pregnant heifers were aborted with an injection of $500 \mu \mathrm{g}$ cloprostenol i.m. and one month later were combined with heifers that did not become pregnant, injected with cloprostenol and re-bred as previously described, resulting in a total of 229 breedings. Aborted heifers were distributed equally at random among breeding groups. The pregnancy rate of aborted heifers in all groups was not different from virgin heifers or from nonpregnant heifers bred once; data from aborted and unaborted heifers were therefore combined.

Oestrus was synchronized in 20 heifers with two injections of cloprostenol i.m. given 12 days apart. Heifers were 
then superovulated with a purified porcine FSH preparation (Folltropin: Vetrapharm Inc., London, Ontario), equivalent to $400 \mathrm{mg}$ NIH-FSH-P as two i.m. injections given daily, with a decreasing dose over 4 days (Gonzales et al., 1990). Ten heifers were inseminated with semen from a control bull and ten heifers were bred with semen from a bull with a high percentage of abnormally condensed nuclei (bulls $\mathrm{C}$ and $\mathrm{K}$, respectively; Table 1). The heifers were slaughtered; unfertilized ova and fertilized ova or embryos were flushed from the reproductive tracts 7 days after insemination and counted. Fertilization rate was calculated as the ratio of the number of fertilized ova or embryos to the total number of oocytes and embryos.

\section{Statistical analysis}

Experiment 1. Correlations between parameters of the routine examination for breeding soundness or the frozen semen evaluation and the Feulgen stain were evaluated by simple regression analysis. Differences between groups were determined by an unpaired two-tailed $t$ test.

Experiment 2. The $\alpha_{\mathrm{t}}$-values for each sample were analysed using SAS Proc Univariate (SAS Procedures Guide). As the values are not normally distributed, the median, the difference between the third and first quartile $\left(Q_{3}-Q_{1}\right)$ as a measure of spread, and the kurtosis, as a descriptive value for the degree that the $\alpha_{\mathrm{t}}$-distributions deviated from a normal distribution, were used for further evaluations. A positive kurtosis indicates a distribution with heavier tails than a normal distribution with the same variance (Snedecor and Cochran, 1991). Correlations between results of the SCSA and the Feulgen stain were evaluated using the Spearman Rank correlation coefficient. Comparisons between groups were made using unpaired two-tailed $t$ tests and Mann-Whitney $U$ tests.

Experiment 3. Pregnancy rates and fertilization rates between heifers bred to different bulls were compared using chi-squared analysis.

Values given are means \pm SEM.

\section{Results}

\section{Experiment 1}

The 70 bulls evaluated by the breeding soundness examination had a mean scrotal circumference of $36.0 \pm 0.3 \mathrm{~cm}$. Individual motility of the spermatozoa was $70.7 \pm 2.0 \%$ and microscopic evaluation of eosin-nigrosin stained semen smears revealed $69.2 \pm 2.3 \%$ of spermatozoa were of normal morphology. After Feulgen staining, $9.8 \pm 1.1 \%$ (range, $0-33 \%$ abnormally condensed nuclei were found. The appearance of abnormally condensed sperm nuclei, as detected by light microscope examination of a Feulgenstained sample and by transmission electron microscopy, is shown (Fig. 1).

Semen from bulls classified as questionable or unsatisfactory potential breeders contained a higher $(P<0.01)$ percentage of
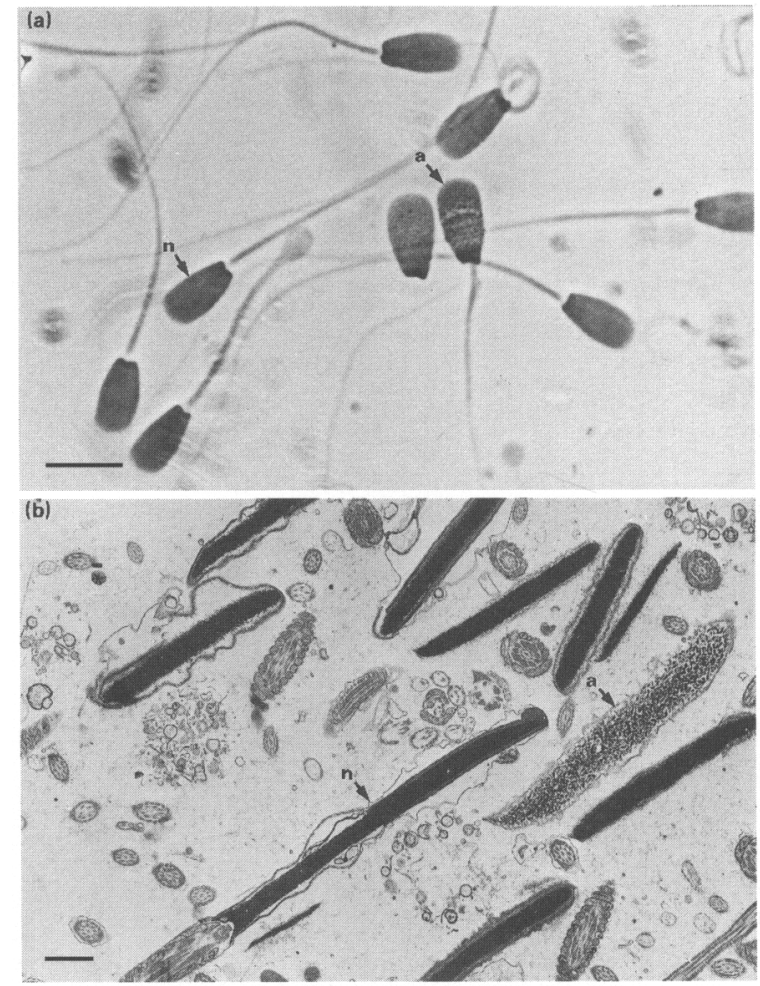

Fig. 1. (a) Normal (n) and abnormally condensed (a) sperm nuclei as viewed under the light microscope (Feulgen stain; scale bar represents $10 \mu \mathrm{m}$ ). (b) Abnormally condensed (a) and normal (n) sperm nuclei as viewed under the electron microscope (scale bar represents $I \mu \mathrm{m}$ ).

spermatozoa with abnormal DNA condensation than did semen from bulls classified as satisfactory potential breeders $[13.5 \pm 1.8 \%$; range, $0-33 \%(n=29)$ and $7.1 \pm 1.2 \%$; range, $0-27 \%(n=41)$, respectively].

The percentage of sperm nuclei with abnormally condensed chromatin was correlated with the percentage of midpiece defects $(r=0.43, \quad P<0.001)$ and loose heads $(r=0.4$, $P<0.001$ ), and inversely correlated with the percentage of spermatozoa of normal morphology $(r=-0.41, P<0.001)$. In $54 \%$ of the samples $>5 \%$ of the spermatozoa, and in $31 \%$ of the samples $>10 \%$ of the spermatozoa had abnormally condensed nuclei.

The evaluation of 571 frozen semen samples from 348 bulls revealed that $72.2 \pm 0.9 \%$ of spermatozoa were of normal morphology and $4.4 \pm 0.5 \%$ had abnormally condensed nuclei. Semen classified as questionable or unsatisfactory contained a higher $(P<0.01)$ percentage of spermatozoa with abnormal DNA condensation than did semen classified as satisfactory [6.8 $\pm 0.9 \%$; range, $0-80 \%(n=168)$ and $2.1 \pm 0.2 \%$; range, $0-29 \%(n=179)$, respectively]. The percentage of abnormally condensed nuclei was inversely correlated with the percentage of intact acrosomes $(r=-0.25, P<0.001)$ and correlated with the percentage of loose heads $(r=0.17, P<0.001)$ and midpiece defects $(r=0.16, P<0.001)$. In $21 \%$ of the samples $>5 \%$ and in $9 \%$ of the samples $>10 \%$ spermatozoa with abnormal DNA condensation were found. Table 2 shows the results for samples frozen in different extenders. 
Table 2. Percentage of spermatozoa with normal morphology, post-thaw motility, intact acrosomes and abnormal DNA in bovine semen samples frozen in milk-based and yolk-based extenders

\begin{tabular}{lcc}
\hline Characteristic & $\begin{array}{c}\text { Milk-based extender } \\
(n=84)\end{array}$ & $\begin{array}{c}\text { Yolk-based extender } \\
(n=244)\end{array}$ \\
\hline Normal morphology & $73.0 \pm 1.7^{\mathrm{a}}$ & $72.3 \pm 1.0^{\mathrm{a}}$ \\
Post-thaw motility & $36.4 \pm 1.6^{\mathrm{a}}$ & $41.8 \pm 0.8^{\mathrm{b}}$ \\
Intact acrosomes & $59.1 \pm 1.3^{\mathrm{a}}$ & $67.5 \pm 0.7^{\mathrm{b}}$ \\
Abnormal DNA & $9.1 \pm 0.2^{\mathrm{a}}$ & $2.7 \pm 0.3^{\mathrm{b}}$ \\
\hline
\end{tabular}
a,b Values with different letters in the same row are significantly different
$(P<0.001)$.

\section{Experiment 2}

The percentage of red fluorescing cells determined by fluorescence microscopy of smears stained with acridine orange was correlated with all forms of nuclear abnormalities seen with the Feulgen stain: the percentage of pyriform heads $\{r=0.61$, $P<0.01)$, pale-staining nuclei $(r=0.57, P<0.01)$, multiple vacuoles $(r=0.68, P<0.01)$, single vacuoles $(r=0.62$, $P<0.01)$, and abnormal DNA $(r=0.69, P<0.001)$. Owing to the small sample size, samples extended in milk- and yolkbased extenders were not analysed separately.

The percentage of abnormally condensed sperm nuclei, as determined by Feulgen staining, was significantly correlated with the kurtosis of the $\alpha_{\mathrm{t}}$-distribution of the sperm cells measured by flow cytometry $(r=-0.64, P<0.01)$. A very narrow abnormal distribution, like the $\alpha_{\mathrm{t}}$-distribution of a sample with predominantly normal, green fluorescing cells, results in tail values very different from the main population and, therefore, a high kurtosis value. The more red fluorescence is emitted by the cells, the more spread out is the main population of the $\alpha_{\mathrm{t}}$-distribution, resulting in a smaller difference between the main population and the tail values and, hence, a lower kurtosis value. Two examples illustrating this relationship are shown (Fig. 2). Samples with more than $10 \%$ abnormally condensed nuclei $(n=8)$ resulted in a significantly lower kurtosis of the $\alpha_{\mathrm{t}}$-distribution than did samples $(n=12)$ with less than $10 \%$ abnormally condensed nuclei $(40.1 \pm 4.4$ versus $56.4 \pm 2.5, P<0.01$ ). The percentage of pyriform sperm heads was also correlated with the dispersion of the $\alpha_{t}$-distribution represented by $Q_{3}-Q_{1}(r=0.55, P<0.05)$. The percentage of nuclear abnormalities other than abnormal condensation and pyriform head shape were not significantly correlated with parameters of the $\alpha_{\mathfrak{t}}$-distributions.

\section{Experiment 3}

The results of the breeding trial with semen from six different bulls are shown in Table 1 .

Superovulation and insemination with semen from bull $\mathrm{K}$ $(67 \%$ abnormally condensed nuclei, see Table 1 ) resulted in a significantly lower fertilization rate than insemination with semen from control bull $\mathrm{C}(32.6 \%$ versus $48.6 \%, P<0.05)$.

\section{Discussion}

The survey of bulls presented to the Veterinary Teaching Hospital for routine breeding soundness evaluation showed that low numbers of abnormally condensed sperm nuclei can be found in otherwise normal semen from potentially fertile bulls. The percentage of spermatozoa with abnormal DNA increases with a disturbance of spermatogenesis. However, the range of the percentage of abnormal nuclei was very similar $(0-30 \%)$ in semen from bulls classified as satisfactory or questionable or unsatisfactory, indicating that high numbers of abnormally condensed sperm nuclei can be found in the absence of other sperm defects observed by routine semen evaluation. A study using acridine orange staining of human semen found spermatozoa of normal morphology with DNA defects resulting in lower fertilization rates in vitro (Liu and Baker, 1992).

The correlation between abnormal nuclear condensation, loose sperm heads and acrosomal integrity indicates that aged spermatozoa often have a malcondensed appearance, which could be due to partial decondensation. However, the correlation with midpiece defects, which occur during the epididymal passage of the spermatozoa, suggests a possible epididymal origin of abnormal nuclear condensation. This contention is in agreement with decondensation studies in vitro that show that the establishment of disulfide crosslinks in bull spermatozoa takes place during sperm maturation in the epididymis (Calvin and Bedford, 1971). In human spermatozoa there is a good correlation between nuclear maturity and chromatin stability (Roux and Dadoune, 1989), indicating that abnormally condensed chromatin might be due to immaturity of the sperm cell.

The results of the frozen semen analysis were very similar to those of fresh semen with regard to sperm morphology and to differences in the percentage of abnormal DNA between samples of different classifications. However, the percentage of abnormally condensed nuclei was lower in frozen than in fresh semen. Selection of bulls in artificial insemination studs for fertility could indirectly have eliminated bulls with higher numbers of abnormally condensed sperm nuclei, whereas the fresh semen was obtained from a fairly unselected population. Alternatively, freezing and thawing of boar and human semen has been shown to increase nuclear stability; furthermore, an overcondensation state of the nuclear chromatin owing to freezing has been postulated (Courtens et al., 1989; Royere et al., 1988, 1991). In agreement with other studies (Senger et al., 1983; Schenk et al., 1987) semen in milk extender showed lower post-thaw viability than did semen in yolk extender. In addition, the percentage of abnormal DNA condensation was three times higher in milk-extended than in yolk-extended semen. These findings are supported by a study using the SCSA on split ejaculates frozen either in heated whole milk or egg-yolk citrate extender, which showed that sperm cells are more susceptible to DNA denaturation when the first extender fraction contained milk. The authors concluded that either milk is detrimental, or yolk is protective to the nuclear chromatin (Karabinus et al., 1991).

In a study with human semen, no correlation was found between acridine orange and Feulgen staining (Peluso et al., 1992), which is in contrast to our results. However, another study evaluating sperm separation procedures for human 

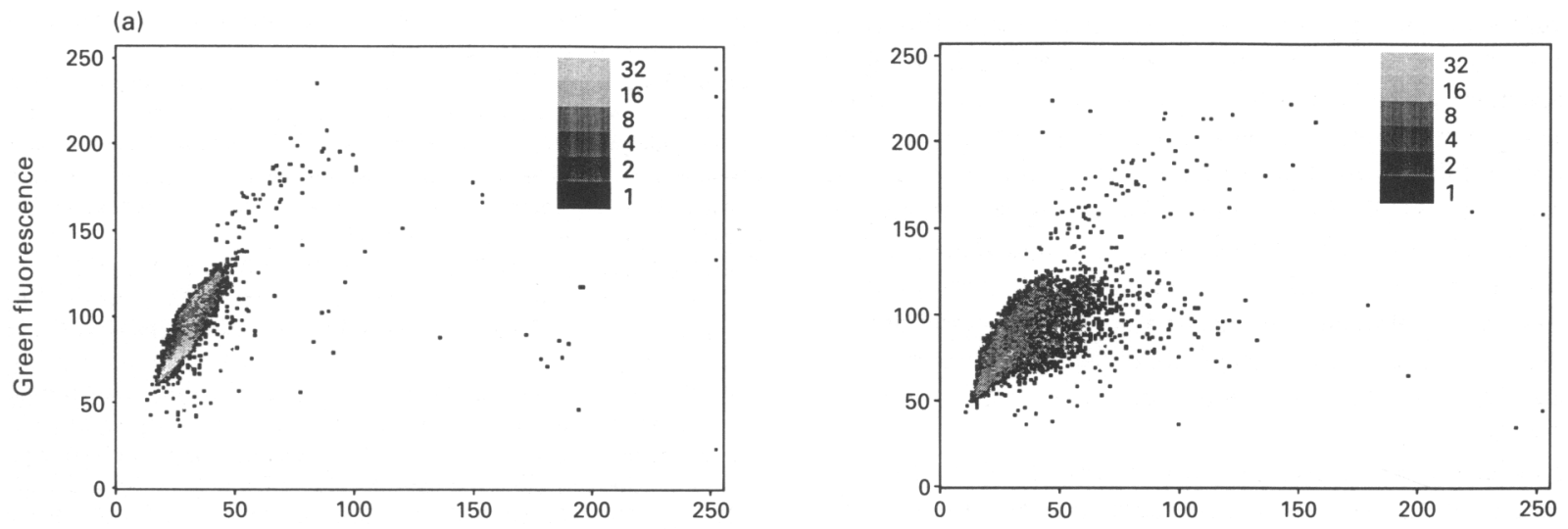

Red fluorescence
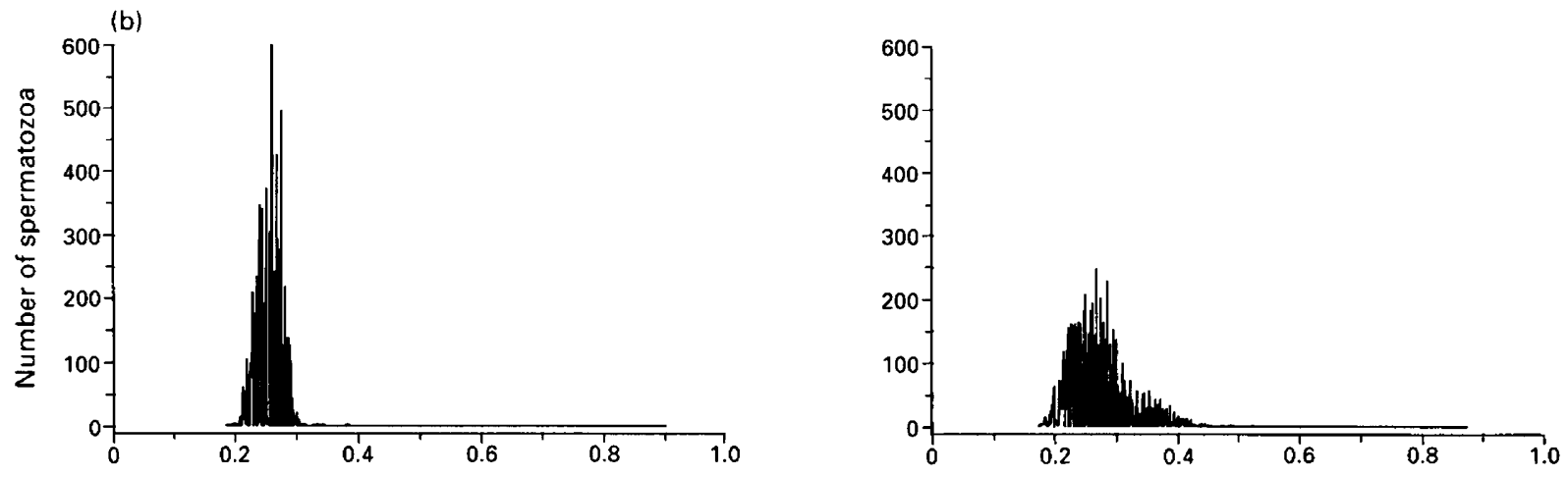

$\alpha_{t}$

Fig. 2. (a) Two-parameter histograms and (b) $\alpha_{\mathrm{t}}$-distributions from two bovine semen samples with sperm nuclear chromatin resistant (left, median $\alpha_{t}=0.26, Q_{3}-Q_{1}=0.03$, kurtosis $=99.71$ ) and susceptible (right, median $\alpha_{t}=0.27, Q_{3}-Q_{1}=0.06$, kurtosis $=6.67$ ) to denaturation.

semen agrees with our results for the acridine orange stain and other parameters of nuclear maturity (LeLannou and Blanchard, 1988). Accordingly, it has been shown by nuclear decondensation and specific staining of thiol groups that the colour of acridine orange fluorescence of the sperm nucleus is related to the extent of disulfide binding of the DNA-associated protamines (Kosower et al., 1992). A comparison of light microscopy or flow cytometry using acridine orange and Feulgen staining for bull semen has not been reported previously.

In previous reports the percentage of cells with $\alpha_{\mathrm{t}}$-values outside the main population was visually assigned to describe the shift from green to red fluorescence in a subpopulation of cells (Ballachey et al., 1987, 1988). We introduced the kurtosis of the abnormal $\alpha_{\mathrm{t}}$-distribution to describe the degree of heterogeneity in the fluorescence of the main cell population quantitatively. The degree of nuclear instability described by variance and kurtosis of the $\alpha_{\mathrm{t}}$-distribution was correlated with nuclear abnormalities seen with the Feulgen stain, indicating that the clumped appearance of the nucleus after Feulgen staining can at least partially be related to decreased structural stability of the nuclear chromatin. This conclusion is supported by the close agreement between the fluorescence microscope results after staining with the acridine orange stain and the
Feulgen stain. The Feulgen staining technique, which is inexpensive and easy to perform, therefore appears to provide information on sperm nuclear integrity comparable to the far more costly and sophisticated flow cytometric analysis.

The importance of abnormally condensed sperm nuclei for fertility in cattle was not conclusively determined. Of the semen with a high percentage of nuclear condensation defects, only one of four resulted in a significantly lower pregnancy rate than that of the control semen. As there were no other detectable differences in the semen used, we cannot explain this result. A larger trial using more breedings per bull might be helpful to establish conclusively the effect of abnormal sperm chromatin condensation on bull fertility.

All insemination doses used in the breeding trial contained at least $3.6 \times 10^{6}$ progressively motile spermatozoa with normal nuclei. Compensation of the defective spermatozoa by normal sperm cells could therefore explain the observed pregnancy rates. This hypothesis is supported by the fact that a lower fertilization rate was observed in superovulated heifers bred with semen with a high percentage of nuclear condensation problems. Since low insemination doses result in lower pregnancy rates in superovulated cows (Hawk et al., 1988), the possible compensation by the normal spermatozoa in the 
insemination dose might not have been sufficient in this case. Further studies in vitro and in vivo are necessary to investigate the mechanism by which this compensation could occur. In a study using human semen, a higher percentage of spermatozoa with normal DNA was bound to the zona pellucida than was present in the insemination medium, indicating selective binding of spermatozoa with normal nuclei (Liu and Baker, 1992). However, in another study no difference in heparin-binding sites was found between spermatozoa with normal and abnormal DNA, and the authors concluded that spermatozoa with abnormal DNA could undergo an acrosome reaction (Peluso et al., 1992).

In conclusion, spermatozoa with abnormal DNA condensation are found in low numbers in semen from normal fertile bulls, but the incidence increases with a disturbance of spermatogenesis. However, high numbers of abnormally condensed nuclei can be found in the absence of other defects. This nuclear defect can lower fertility, but appears to be compensated for by increasing the numbers of normal spermatozoa in the insemination dose. Abnormal DNA condensation might be at least partially of epididymal origin. The results of the flow cytometric SCSA correlate with the results of the Feulgen stain, indicating that semen with abnormally condensed nuclei has a decreased structural integrity of the nuclear chromatin. We therefore consider the Feulgen technique to be a valuable method of gaining information on nuclear integrity for evaluation of bovine spermatozoa.

The authors thank T. Beskorwayne for technical help with the flow cytometry, S. Caldwell for preparation of the electron micrographs, $W$. Kerr for care of the animals, and M. Campos and D. P. Evenson for valuable advice. Estrumate was generously supplied by Cooper's Agropharm Inc., Ajax, Ontario, and Folltropin by Vetrapharm Inc., London, Ontario. The study was supported by the Canadian Association of Animal Breeders.

\section{References}

Balhorn R, Corzett M, Mazrimas J and Watkins B (1991) Identification of bull protamine disulfides Biochemistry 30 175-181

Ball L, Ott RS, Mortimer RG and Simons JC (1983) Manual for breeding soundness examination of bulls Journal of the Society for Theriogenology 12 I-65

Ballachey BE, Miller HL, Jost LK and Evenson DP (1986) Flow cytometry evaluation of testicular and sperm cells obtained from bulls implanted with zeranol Journal of Animal Science 63 995-1004

Ballachey BE, Hohenboken WD and Evenson DP (1987) Heterogeneity of sperm nuclear chromatin structure and its relationship to bull fertility Biology of Reproduction 36 915-925

Ballachey BE, Evenson DP and Saake RG (1988) The sperm chromatin structure assay. Relationship with alternate tests of semen quality and heterospermic performance of bulls Journal of Andrology 9 109-115

Barth AD (1989) Evaluation of frozen bovine semen. In Proceedings of the Annual Meeting of the Society for Theriogenology, Idaho pp 92-99. Society for Theriogenology, Hastings, Nebraska

Barth AD (1993) Evaluation of frozen bovine semen by the veterinary practitioner. In Theriogenology Handbook B-9. Society for Theriogenology, Hastings, Nebraska

Barth AD and Oko RJ (1989a) Preparation of semen for morphological examination. In Abnormal Morphology of Bovine Spermatozoa pp 8-18. Iowa State University Press, Ames, IA

Barth AD and Oko RJ (1989b) Defects of the sperm head. In Abnormal Morphology of Bovine Spermatozoa pp 130-192. Iowa State University Press, Ames, IA
Brachet J and Hulin N (1969) Binding of tritiated actinomycin and cell differentiation Nature 222 481-482

Calvin HI and Bedford JM (1971) Formation of disulfide bonds in the nucleus and accessory structures of mammalian spermatozoa during maturation in the epididymis Journal of Reproduction and Fertility Supplement 13 65-75

Chenoweth PJ, Hopkins FM, Spitzer JC and Larsen RE (1993) Guidelines for using the bull breeding soundness evaluation form. Theriogenology Handbook B-10, Society for Theriogenology, Hastings, Nebraska

Courtens JL, Paquignon M, Blaise F, Ekwall H and Ploen L (1989) Nucleus of the boar spermatozoon: structure and modifications in frozen, frozen-thawed, or sodium dodecyl sulfate-treated cells Molecular Reproduction and Development $1264-277$

Cran DG and Massanyi L (1988) Two cases of multiple abnormalities in testicular and ejaculated bull spermatozoa Theriogenology 30 1121-1126

Darzynkiewicz Z and Kapuscinski J (1990) Acridine orange: a versatile probe of nucleic acids and other cell constituents. In Flow Cytometry and Sorting 2nd Ed̉n pp 291-314 Eds MR Melamed, T Lindmo and ML Mendelsohn. Wiley-Liss, New York

Darzynkiewicz Z., Gledhill BL and Ringertz NR (1969) Changes in deoxyribonucleoprotein during spermiogenesis in the bull. ${ }^{3} \mathrm{H}$-Actinomycin $\mathrm{D}$ binding capacity Experimental Cell Research $\mathbf{5 8} 435$

Darzynkiewicz Z, Traganos F, Sharpless T and Melamed MR (1975) Thermal denaturation of DNA in situ as studied by acridine orange staining and automated cytofluorometry Experimental Cell Research 90 411-428

Evenson DP (1990) Flow cytometric analysis of male germ cell quality Methods in Cell Biology 33 401-410

Evenson DP and Melamed MR (1983) Rapid analysis of normal and abnormal cell types in human semen and testis biopsies by flow cytometry Joumal of Histochemistry and Cytochemistry 31 248-253

Evenson DP and Thompson L (1991) Flow cytometric analysis of boar sperm chromatin structure as related to cryopreservation and fertility Reproduction in Domestic Animals, Supplement 1 165-183

Evenson DP, Darzynkiewicz Z and Melamed MR (1980) Relation of mammalian sperm chromatin heterogeneity to fertility Science $2101131-1133$

Evenson DP, Higgins PH, Grueneberg D and Ballachey BE (1985) Flow cytometric analysis of mouse spermatogenic function following exposure to ethylnitrosourea Cytometry 6 238-253

Feulgen R and Rossenbeck H (1924) Mikroskopisch-chemischer Nachweis einer Nukleinsaeure vom Typus der Thymonucleinsaeure und die darauf beruhende elektive Faerbung von Zellkernen in mikroskopischen Praeparaten Zeitschrift fuer Physiologische Chemie 135 203-248

Gledhill BL (1970) Enigma of spermatozoal deoxyribonucleic acid and male infertility: a review American Journal of Veterinary Research 31 539-545

Gledhill BL, Gledhill MP, Rigler R, Jr and Ringertz NR (1966) Atypical changes of deoxyribonucleo-protein during spermiogenesis associated with a case of infertility in the bull Joumal of Reproduction and Fertility 12 575-578

Gledhill BL, Darzynkiewicz Z and Ringertz NR (1971) Changes in deoxyribonucleo-protein during spermiogenesis in the bull: increased $\left[{ }^{3} \mathrm{H}\right]$ Actinomycin $\mathrm{D}$ binding to nuclear chromatin of morphologically abnormal spermatozoa Joumal of Reproduction and Fertility 26 25-28

Gonzales A, Lussier JG, Carruthers TD, Murphy BD and Mapletoft RJ (1990) Superovulation of beef heifers with Folltropin: a new FSH preparation containing reduced LH activity Theriogenology 33 519-529

Hawk HW, Conley HH, Wall RJ and Whitaker RO (1988) Fertilization rates in superovulating cows after deposition of semen in the infundibulum, near the uterotubal junction or after insemination with high numbers of sperm Theriogenology 29 1131-1142

Hrudka F, Betsch JM and Kenney RM (1991) Anomalies of centriolar derivatives manifest in spermatic flagella and respiratory cilia of the stallion Archives of Andrology 27 161-175

Karabinus DS, Evenson DP, Jost LK, Baer RK and Kaproth MT (1990) Comparison of semen quality in young and mature holstein bulls measured by light microscopy and flow cytometry Journal of Dairy Science 73 2264-2371

Karabinus DS, Evenson DP and Kaproth MT (1991) Effects of egg yolk-citrate and milk extenders on chromatin structure and viability of cryopreserved bull sperm Journal of Dairy Science 74 3836-3848

Kosower NS, Katayose H and Yanagimachi R (1992) Thiol-disulfide status and acridine orange fluorescence of mammalian sperm nuclei Journal of Andrology 13 342-348

LeLannou D and Blanchard Y (1988) Nuclear maturity and morphology of human spermatozoa selected by Percoll density gradient centrifugation or swim-up procedure Journal of Reproduction and Fertility 84 551-556 
Liu DY and Baker HWG (1992) Sperm nuclear chromatin normality: relationship with sperm morphology, sperm zona-pellucida binding, and fertilization rate in vitro Fertility and Sterility 58 1178-1184

McCosker PJ (1969) Abnormal spermatozoan chromatin in infertile bulls Joumal of Reproduction and Fertility 18 363-365

Ott RS (1986) Breeding soundness examination of bulls. In Current Therapy in Theriogenology (2nd Edn) pp 125-136 Ed. DA Morrow. W.B. Saunders Co., Philadelphia

Peluso JJ, Luciano AA and Nulsen JC (1992) The relationship between alterations in spermatozoal deoxyribonucleic acid, heparin binding sites, and semen quality Fertility and Sterility $57665-670$

Royere D, Hamamah S, Nicolle JC, Barthelmy C and Lansac J (1988) Freezing and thawing alter chromatin stability of ejaculated human spermatozoa: fluorescence acridine orange staining and Feulgen DNA cytophotometric studies Gamete Research 21 51-57

Royere D, Hamamah S., Nicolle IC and Lansac J (1991) Chromatin alterations induced by freeze-thawing influence the fertilizing ability of human sperm International Journal of Andrology 14 328-332

Roux C and Dadoune JP (1989) Use of the acridine orange staining on smears of human spermatozoa after heat-treatment: evaluation of the chromatin condensation Andrologia 21 275-281
SAS Procedures Guide, Version 6 (3rd Edn) (1990) Statistical Analysis System Institute Inc., Cary, NC

Schenk JL, Amann RP and Allen CH (1987) Effects of extender and insemination dose on post-thaw quality and fertility of bovine sperm Joumal of Dairy Science 70 1458-1464

Senger PL, Mitchell JR and Almquist JO (1983) Influence of cooling rates and extenders upon post-thaw viability of bovine spermatozoa packaged in .25 and $.5 \mathrm{ml}$ straws Journal of Animal Science 56 1261-1268

Snedecor GW and Cochran WG (1991) Tests of hypotheses. In Statistical Methods (8th Edn) pp 64-82. Iowa State University Press, Ames, IA

Tejada RI, Mitchell JC, Norman A, Marik JJ and Friedman S (1984) A test for the practical evaluation of male fertility by acridine orange $(\mathrm{AO})$ fluorescence Fertility and Sterility $\mathbf{4 2} 87-91$

Wagner TE and Minhas BS (1982) Condensation and decondensation of spermatozoal DNA. In Prospects for Sexing Mammalian Sperm pp 49-60 Eds RP Amman and GE Seidel. Colorado Associated Press, Boulder, CO

Ward WS and Coffey DS (1991) DNA packaging and organization in mammalian spermatozoa. Comparison with somatic cells Biology of Reproduction $44569-574$ 